\title{
Orbital and Choroidal Plasmacyto- ma in Recurrent Multiple Myeloma: A Case Report
}

\section{Dear Editor,}

Multiple myeloma is a blood disease in which plasma cells proliferate abnormally and it accounts for approximately $1 \%$ of all cancers and $10 \%$ of hematologic malignancies [1]. Multiple myeloma is characterized by bone infiltration and it can also appear in the form of plasma cell tumors in many organs. Secondary ocular involvement is rare, but it can occur in the orbit, extraocular muscles, and within the uveal tract [2]. Intraocular plasmacytoma is very rare, but it has been reported in the iris, ciliary body, and choroid [3]. Multiple myeloma is usually treated with systemic chemotherapy and bone marrow transplantation. Focal plasmacytomas are generally treated with local radiation therapy $[4,5]$. We report a case of plasmacytoma that affected both the choroid and orbit in recurrent multiple myeloma.

A 56-year-old woman was diagnosed with multiple myeloma in April 2008. In October 2008, she underwent autologous peripheral hematopoietic stem cell transplantation. She received an allogeneic hematopoietic stem cell transplant in November 2013. However, multiple myeloma recurred in 2014. She was commissioned to our department for a 2-day history of orbital swelling, which was initiated during chemotherapy (2nd cycle of carfilzomib/dexamethasone after 9th cycle of lenalidomide/dexamethasone) because of recurrent multiple myeloma in June, 2018.

At the time of presentation, her visual acuity was $20 / 20$ in both eyes. The intraocular pressure was $8 / 9 \mathrm{mmHg}$. There was no palpable mass, but mild swelling and a slight heating sensation were observed on the left lower eyelid. The eyeball movement was normal, and there was no proptosis. Lower orbital mass, inferior rectus muscle thicken-

Received: May 3, 2021 Final revision: June 22, 2021

Accepted: June 24, 2021

(C) 2021 The Korean Ophthalmological Society

This is an Open Access article distributed under the terms of the Creative Commons Attribution Non-Commercial License (http://creativecommons.org/licenses /by-nc/3.0/) which permits unrestricted non-commercial use, distribution, and reproduction in any medium, provided the original work is properly cited. 

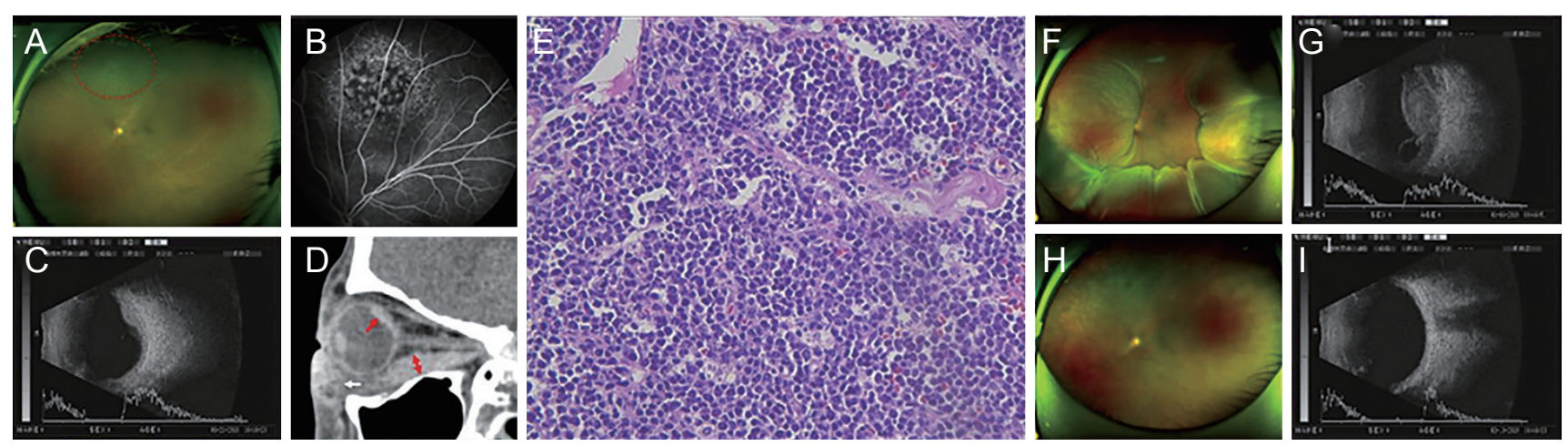

Fig. 1. Imaging and histological examinations of plasmacytomas. (A-D) Choroidal and orbital plasmacytoma at the first presentation. (E) Histological examination of periorbital mass. (F,G) Worsening of choroidal plasmacytoma after follow up loss. (H,I) After external beam radiotherapy. (A) Wide-field fundus photography of the left eye shows round choroidal mass of mid-peripheral fundus, stippled pigmentation over the lesion (red dotted circle). (B) Fluorescein angiography of the left eye shows speckled hyperfluorescence of the lesion. (C) Ultrasonography of the left eye (B-scan mode) shows dome-shaped choroidal mass. The sclera appears normal. A-scan mode shows high reflectivity of the lesion. (D) Orbital computed tomography demonstrates homogenous enhancement of choroidal mass (red arrow) and anterior orbital mass (white arrow) and thickened inferior rectus muscle (red double headed arrows). (E) Periorbital mass with homogenous plasmacytic infiltrate (hematoxylin-eosin stain, $\times 400$ ). (F) Wide-field fundus photograph of the left eye shows large choroidal mass with subretinal fluid. (G) B-scan ultrasonography demonstrates enlarged choroidal mass lesions with acoustic solidity. With A-mode, the spike amplitude within the mass shows medium-high peak. $(\mathrm{H})$ Wide-field fundus photography of the left eye shows complete regression of choroidal mass. (I) No choroidal mass is found on B-scan ultrasonography after radiotherapy.

mass revealed a plasmacytoma and the orbital mass was found simultaneously with choroidal mass. The choroidal mass worsened with worsening of systemic multiple myeloma, and the imaging findings showed features of choroidal plasmacytoma (Fig. 1F, 1G). According to the facts that above mentioned, it is highly possible to estimate that the choroidal mass is also plasmacytoma.

This is a very rare case of secondary ocular plasmacytoma that affected both the choroid and orbit. Secondary ocular plasmacytoma, despite its rarity, should be considered in patients with multiple myeloma when an amelanotic choroidal mass is observed. When ocular plasmacytoma occurs, it should be monitored and treated appropriately.

\section{Ji Ho Choi \\ Department of Ophthalmology, Jeonbuk National University Medical School, Jeonju, Korea}

\section{Joon Hyung Kim}

Department of Ophthalmology, Seoul National University

Hospital, Seoul, Korea

\section{Jin Gu Jeong}

Department of Ophthalmology, Jeonbuk National University Medical School, Jeonju, Korea

E-mail: jingu@jbnu.ac.kr

\section{Conflict of Interest}

No potential conflict of interest relevant to this article was reported.

\section{References}

1. Salmon SE, Cassady JR. Plasma cell neoplasms. In: DeVita VT, Hellman S, Rosenberg SA, editors. Cancer: principles and practice of oncology. Vol. 2. 5th ed. Philadelphia: Lippincott-Raven Publishers; 1997. p. 2344-96.

2. Adkins JW, Shields JA, Shields CL, et al. Plasmacytoma of the eye and orbit. Int Ophthalmol 1996-1997;20:339-43.

3. Shields JA, Shields CL. Intraocular involvement with other lymphoid lesions. In: Shields JA, Shields CL. Intraocular tumors: an atlas and textbook. Philadelphia: Lippincott Williams \& Wilkins; 2006. p. 504-33.

4. Thoumazet F, Donnio A, Ayeboua L, et al. Orbital and muscle involvement in multiple myeloma. Can J Ophthalmol 2006;41:733-6.

5. Honavar SG, Shields JA, Shields CL, et al. Extramedullary plasmacytoma confined to the choroid. Am J Ophthalmol 2001;131:277-8. 